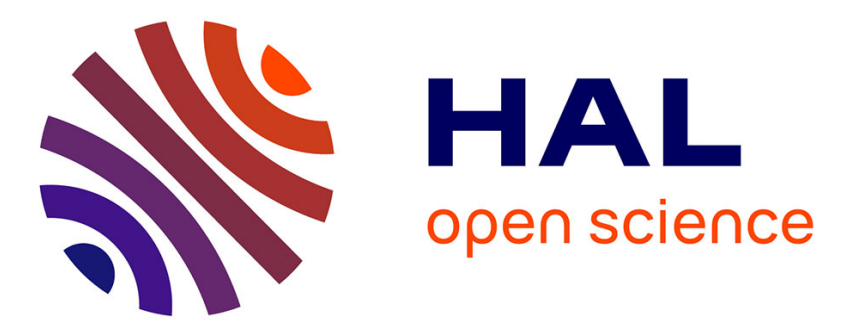

\title{
Scaling invariance of fatigue crack growth in gigacycle loading regime
}

\author{
V. Oborin, M. Bannikov, O. Naimark, Thierry Palin-Luc
}

\section{To cite this version:}

V. Oborin, M. Bannikov, O. Naimark, Thierry Palin-Luc. Scaling invariance of fatigue crack growth in gigacycle loading regime. Tech. Phys. Lett., 2010, 36 (11), pp.1061-1063. 10.1134/S106378501011026X . hal-01251159

\section{HAL Id: hal-01251159 \\ https://hal.science/hal-01251159}

Submitted on 5 Jan 2016

HAL is a multi-disciplinary open access archive for the deposit and dissemination of scientific research documents, whether they are published or not. The documents may come from teaching and research institutions in France or abroad, or from public or private research centers.
L'archive ouverte pluridisciplinaire HAL, est destinée au dépôt et à la diffusion de documents scientifiques de niveau recherche, publiés ou non, émanant des établissements d'enseignement et de recherche français ou étrangers, des laboratoires publics ou privés. 


\title{
Scaling Invariance of Fatigue Crack Growth in Gigacycle Loading Regime
}

\author{
V. Oborin*, M. Bannikov, O. Naimark, and T. Palin-Luc \\ Institute of Continuous Media Mechanics, Ural Branch, Russian Academy of Sciences, Perm, 614013 Russia \\ Laboratoire Matériaux Endommagement Fiabilité et Ingénierie des Procédés, \\ Ecole Nationale Supérieure des Arts et Métiers, F-33405 Talence Cedex, France \\ *e-mail: oborin@icmm.ru \\ Received June 10, 2010
}

\begin{abstract}
The role of the collective behavior of defect ensembles at the crack tip and the laws of fatigue crack propagation in R4 high-strength steel have been studied under conditions of symmetric tension-compression gigacycle loading at $20 \mathrm{kHz}$. At every stage of the fatigue crack growth, replicas from the sample side surface were taken and studied by the method of three-dimensional relief profilometry (using NewView interferometer profilometer) so as to study the scaling-invariant laws of defect-related structure evolution.
\end{abstract}

DOI: $10.1134 / \mathrm{S} 106378501011026 \mathrm{X}$

The task of assessing the working resource of important structures, in particular, those for aircraft engines, poses qualitatively new basic problem related to evaluation of the reliability of materials under conditions of cyclic loading in excess of $10^{6}-10^{10}$ cycles, which refer to the field of so-called gigacycle fatigue. This interest is related to the fact that the resource of loading for many important parts operating under conditions of cyclic loading exceeds the so-called multicycle range. the behavior of materials in the range of gigacycle fatigue reveals some qualitative changes in the laws governing both the nucleation of cracks (in the bulk of a sample) and their propagation, which are related to changes in the mechanisms of fatigue crack nucleation and propagation. In the range of gigacycle loading, the fatigue curve exhibits discontinuities and the behavior shows evidence of a significant increase in the role of environment, so that the problem acquires an interdisciplinary character.

The stages of material fracture in the range of gigacycle loading are classified based on the structural signs of damage related to a broad spectrum of spatial scales, including persistent slip bands (PSBs), fatigue striations, microcracks (formed as a result of PSB crossing), and grain-boundary defects. The main damage refers to the defect scales within $0.1 \mu \mathrm{m}-$ $1 \mathrm{~mm}$, which are significantly smaller than those detected by the standard methods of nondestructive testing used for the conventional monitoring of reliability, in particular, during the exploitation of buildings.

An effective method for investigating the role of initial structural heterogeneity, monitoring the accumulation of defects on various scales (dislocation ensembles, micropores, microcracks), and determin- ing critical conditions for the transition from dispersed to macroscopic fracture is offered by the quantitative fractography. This technique reveals the characteristic stages of fracture (crack nucleation and propagation), thus providing a base for evaluating the temporal resource of materials and structures under conditions of gigacycle loading.

The approach to characterization of the fracture surface morphology in terms of spatiotemporal invariants was originally proposed by Mandelbrot [1]. This method is based on an analysis of the relief of a fracture surface, which exhibits the property of self-affinity as manifested by the invariant characteristics of the surrace relief (roughness) over a broad spectrum of spatial scales. On the other hand, these characteristics reflect a correlated behavior of defects on various scaling levels.

The universal character of kinetic laws establishing a relationship between the growth rate $d l / d N$ of a fatigue cracks and a change in the stress intensity coefficient $\Delta K$ has been extensively studied both experimentally and theoretically. The power laws originally established by Paris [2] (and presently referred to as the Paris law) reflect the automodel (self-similar) nature of development of fatigue cracks. This law is related to a nonlinear character of damage development in the vicinity of the crack tip (called the "process zone" [2]):

$$
d l / d N=C(\Delta K)^{m},
$$

where $C$ and $m$ are the experimentally determined constants. For a broad class of materials and wide range of crack propagation velocities under multicycle fatigue conditions, the exponent is typically close to $m=3-4$. 


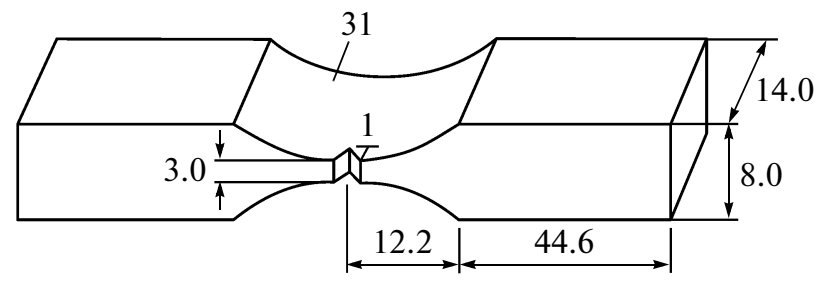

Fig. 1. Schematic diagram and characteristic dimensions of the initial sample (in millimeters).

The universal nature of the Paris law was interpreted [3] based on the self-similar laws of damage development and fracture focus formation in the form of "dissipative structures" representing ensembles of defects localized on the spectrum of spatial scales. The formation of these structures reveals a critical character of the transition from dispersed to macroscopic fracture as manifested by the structural-scaling transitions [4]. According to these notions, the propagation of cracks is related to establishing a long-range correlation interaction in multiscale ensembles of dissipative structures. This interaction which can be characterized by a certain correlation scale, above which the interaction proceeds to a scale that determines the subsequent increment in the length of the propagating crack (size of the "process zone"). This assumption concerning the critical conditions for the aforementioned transition was used in interpretation of the experimental data so as to explain the self-similar scenario of fatigue crack propagation in a steel sample under conditions of gigacycle loading.

The samples of R4 high-strength steel (with a room-temperature fatigue limit of $600 \mathrm{MPa}$ for $10^{6}$ cycles at $10 \mathrm{~Hz}$ ) were tested under fatigue loading conditions with symmetric tension-compression cycling at $20 \mathrm{kHz}$ (gigacycle loading regime) on an original setup [5]. The testing machine consisted of the following main parts: (i) generator, which converted $50-\mathrm{Hz}$ oscillations into an ultrasonic electric sinusoidal signal with a frequency of $20 \mathrm{kHz}$; (ii) piezoelectric transducer, which generated longitudinal ultrasonic waves and produced mechanical action at a frequency of $20 \mathrm{kHz}$; and (iii) ultrasonic waveguide, which increased the amplitude of mechanical stresses in the (working) central part of the sample.

At the initial stage, a fatigue crack with a length of $\sim 1.5 \mathrm{~mm}$ was nucleated, the subsequent growth of which was controlled by varying the amplitude of oscillations. The corresponding stress intensity coefficient $\Delta K$ was calculated by the following formula:

$$
\Delta K=\frac{E}{1-v^{2}} \sqrt{\frac{\pi}{l}} U_{0} Y(l / w),
$$

where $E$ is the Young's modulus, $v$ is the Poisson ratio, $U_{0}$ is the amplitude of oscillations, $Y$ is the polynomial factor, and $w$ is the sample width. For a given sample geometry (Fig. 1) the polynomial factor was as follows:

$$
\begin{gathered}
Y(l / w)=0.635(l / w)+1.731(l / w)^{2} \\
-3.979(l / w)^{3}+1.963(l / w)^{4} .
\end{gathered}
$$

After every step of the fatigue crack growth, replicas from the sample side surrace were taken in order and to study the morphology of defect structures at the crack tip. Figure 2 shows the typical surface relief observed on a sample replica, which was obtained using a high-resolution NewView interferometer. This profilometer ensured a vertical resolution of $0.1 \mathrm{~nm}$ and a lateral resolution of $0.5 \mu \mathrm{m}$. These patterns were analyzed using the methods of correlation analysis for determining the conditions of scaling invariance in the ensembles of structures, which were assumed to govern the subsequent stage of crack development.

One-dimensional profiles obtained for the surrace of replicas were used to construct autocorrelation functions (ACFs) of the following type

$$
\Psi(r)=\int f(x) f(x-r) d x .
$$

The first nonzero value of the ACF was assumed to determine the critical scale $l_{\text {sc }}$ for establishing longrange correlation interactions in the ensembles of defects formed in a process zone scale $L_{\mathrm{pz}}$ (Fig. 2). The

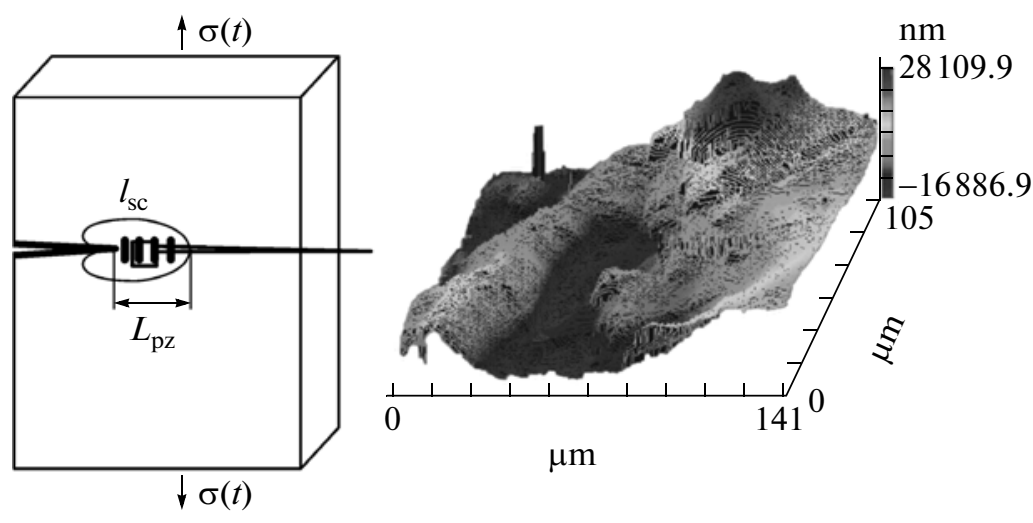

Fig. 2. Schematic diagram showing a region at the crack tip and typical image of the replica (see text for explanations). 
Values of parameters at various stages of fatigue crack development

\begin{tabular}{c|c|c|c|c}
\hline $\begin{array}{c}\Delta K, \\
(\mathrm{MPa} \sqrt{\mathrm{m}})\end{array}$ & $\begin{array}{c}\Delta l \times 10^{4}, \\
\mathrm{~m}\end{array}$ & $\Delta N \times 10^{-5}$ & $\begin{array}{c}d l / d N \times \\
10^{12}\end{array}$ & $\begin{array}{c}l_{\mathrm{sc}} \times 10^{4}, \\
\mathrm{~m}\end{array}$ \\
\hline 6.200 & 2.398 & 20.5 & 117 & 0.033 \\
5.890 & 1.997 & 2.82 & 708 & 3.4 \\
5.596 & 2.200 & 4.74 & 464 & 2.2 \\
5.316 & 2.505 & 4.22 & 593 & 5.5 \\
4.797 & 3.003 & 2.75 & 1090 & 2.6 \\
4.558 & 3.597 & 7.13 & 505 & 2.5 \\
4.330 & 2.403 & 433 & 5.56 & 2.6 \\
\hline
\end{tabular}

values of the critical scale $l_{\mathrm{sc}}$ for various stages of crack propagation are presented in the table.

Manifestations of the self-similar nature of the fatigue crack growth were studied using methods of the theory of similarity and dimensionality $[6,7]$. The crack growth rate was defined as $a=d l / d N$ (where $l$ is the crack length and $N$ is the number of cycles) and studied as for correlation with the following parameters: $a_{1}=\Delta K$, stress intensity coefficient; $a_{2}=E$, Young's modulus; $a_{3}=l_{\mathrm{sc}}$, correlation scale in the ensemble of defects; $a_{4}=L_{\mathrm{pz}}$, the scale related to the process zone.

Using the $\Pi$-theorem and taking into account the dimensionality of variables $[d l / d N]=L,[\Delta K]=$ $F L^{-3 / 2},\left[l_{\mathrm{sc}}\right]=\left[L_{p z}\right]=L$, and $[E]=F L^{-2}$, the kinetic equation for the crack growth

$$
\begin{aligned}
& \frac{d l}{d N}=\Phi\left(\Delta K, E, l_{\mathrm{sc}}, L_{\mathrm{pz}}\right) \\
& \ln \frac{\Delta K}{E \sqrt{l_{\mathrm{sc}}}} \\
& \begin{array}{rrrrrrrr}
-5.8 & -5.7 & -5.6 & -5.5 & -5.4 & -5.3 & -5.2 & -5.1 \\
\hline
\end{array} \\
& \begin{array}{r}
y=2.2931 x+1.465 \\
R^{2}=0.7845
\end{array} \quad \begin{array}{l}
-9 \\
-10 \\
-11 \\
-12 \\
-13 \\
-14 \\
\ln \frac{d l}{d N}
\end{array}
\end{aligned}
$$

Fig. 3. Rectified plot of relation (6). can be rewritten as follows:

$$
\frac{d l}{d N} \frac{1}{l_{\mathrm{sc}}}=\bar{\Phi}\left(\frac{\Delta K}{E \sqrt{l_{\mathrm{sc}}}}, \frac{L_{\mathrm{pz}}}{l_{\mathrm{sc}}}\right)
$$

Estimation of the values $\Delta K /\left(E \sqrt{l_{\mathrm{sc}}}\right) \ll 1$ and $L_{\mathrm{pz}} / l_{\mathrm{sc}} \gg 1$ suggest an intermediate-asymptotic character of the crack growth kinetics for Eq. (4) in the following form:

$$
\frac{d \bar{l}}{d N}=\left(\frac{\Delta K}{E \sqrt{l_{\mathrm{sc}}}}\right)^{\alpha}\left(\frac{L_{\mathrm{pz}}}{l_{\mathrm{sc}}}\right)^{\beta},
$$

where $\bar{l}=l / l_{\mathrm{sc}}$. Introducing the parameter $C=$ $\left(L_{\mathrm{pz}} / l_{\mathrm{sc}}\right)^{\beta}$, we can reduce the scaling relation (3) to the following form analogous to the Paris law:

$$
\frac{d \bar{l}}{d N}=C\left(\frac{\Delta K}{E \sqrt{l_{\mathrm{sc}}}}\right)^{\alpha},
$$

where $\alpha$ is a universal exponent.

Using relation (6), which constructed based on the results experimental investigation of the fatigue crack growth kinetics with allowance for the calculated $l_{\mathrm{sc}}$ values, it is possible to estimate the exponent as $\alpha \sim$ 2.3, which corresponds to the slope of the straight line in the rectifying coordinates (Fig. 3). A difference of the exponent $\alpha \sim 2.3$ from values obtained in the regimes of multicycle fatigue testing suggests that there are certain specific features in the formation of fracture regions in the vicinity of crack tip under conditions of gigacycle loading.

Acknowledgments. This study was supported in part by the Russian Foundation for Basic Research, Project nos. 08-01-00699, 09-01-92005-NNS_a, and 09-01-92441-KE_a.

\section{REFERENCES}

1. B. B. Mandelbrot, The Fractal Geometry of Nature (W.H. Freeman, New York, 1983), p. 468.

2. P. Paris, D. Lados, and H. Tad, Eng. Fract. Mech. 75, 299 (2008).

3. J. L. Lataillade and O. B. Naimark, Phys. Mesomech. 7 (4), 55 (2004).

4. O. B. Naimark, in Advances in Multifield Theories of Continua with Substructure, Ed. by G. Capriz and P. Mariano (Birkhauser, Boston, 2003), pp. 75-114.

5. C. Bathias, Int. J. Fatigue 28, 1438 (2006).

6. G. I. Barenblatt, Int. J. Fracture 138, 19 (2006).

7. R. O. Ritchie, Int. J. Fracture 132, 197 (2005). 